\title{
Further Studies of Ultraviolet-sensitive Mutants of Escherichia coli Strain B
}

\author{
By RUTH F. HILL AND ROSE R. FEINER \\ Radiological Research Laboratory, Department of Radiology, Columbia University, \\ New York City, U.S.A.
}

(Received 17 October 1963)

\section{SUMMARY}

A group of twelve ultraviolet-sensitive mutants has been isolated after u.v. irradiation of Escherichia coli strain в. The use of crystal violet during irradiation and subsequent growth appears to increase the frequency of such mutants among colonies formed by surviving cells. This effect may be due to post-irradiation selection. Eleven of the mutants were more crystal violet resistant than their parent.

The mutants were compared by determining their u.v. survival curves, the extent of elongation after u.v. irradiation, their ability to repair u.v. induced damage to bacteriophage $\mathbf{T} 1$, and their resistance to furacin. They comprised nine different phenotypes. In all but one case, the mutants differed from the parent in more than one property.

\section{INTRODUCTION}

The genetic basis of ultraviolet (u.v.) sensitivity in the bacterium Escherichia coli has been established in a number of recent investigations (Adler \& Copeland, 1962; Rörsch, Edelman, van der Kamp \& Cohen, 1962; Howard-Flanders, Boyce, Simson \& Theriot, 1962; Rörsch, Edelman \& Cohen, 1963). These studies have usually consisted in the genetic transfer of properties previously found in some u.v. sensitive or u.v. resistant mutants and the subsequent demonstration that the recipient organism has acquired the expected change in u.v. sensitivity. The properties employed have been the ability to repair u.v. induced damage in bacteriophage and the formation of snake-like filaments after u.v. irradiation. The former property is thought to be dependent upon the organism's ability to repair u.v. induced damage to DNA; the latter is considered to be indicative of u.v. induced damage to cell division.

It is apparent from these studies that u.v. radiation produces more than one effect. Hence it might be expected that mutants whose increased u.v. sensitivity is due to increased susceptibility to one effect should be like the parent strain with respect to susceptibility to other effects. The present report concerns an investigation of this question in the case of u.v. sensitive mutants derived from E. coli strain B.

\section{METHODS}

The bacterial strains employed were $\boldsymbol{E}$. coli B, a u.v. resistant (B/r) mutant, and twelve u.v. sensitive $\left(\mathrm{B}_{\mathrm{S}}\right)$ mutants. Two of the u.v. sensitive mutants, $\mathrm{B}_{\mathrm{B-1}}$ and $\mathrm{B}_{\mathrm{s}-2}$, had been isolated previously and some of their properties described (Hill \& Simson, 
1961). The ten additional mutants were isolated as follows. Cultures of в were grown to the logarithmic stage by aeration in nutrient broth. Samples containing $10^{6}-10^{7}$ organisms were spread on nutrient broth agar. In some isolation experiments the nutrient broth agar was supplemented with crystal violet. The significance of this will be discussed later.

After spreading, the organisms were u.v. irradiated with doses allowing $10^{-4}-10^{-5}$ survival and incubated at $37^{\circ}$. Colonies formed by surviving cells were subcultured in nutrient broth and loopfuls were spread over small areas on nutrient broth agar. These areas were u.v. irradiated with a dose $\left(160 \mathrm{ergs} / \mathrm{mm} .{ }^{2}\right)$ allowing $1 \%$ survival of B cells. After $3 \mathrm{hr}$ incubation, the spread areas were examined microscopically. Areas containing very short cells or mixtures of short cells and slightly elongated cells were tentatively diagnosed as containing $\mathbf{B}_{\mathbf{S}}$ mutants, in comparison with areas showing extremely long filaments ('snakes'), which is typical of в at the given dose, or with areas showing a moderate amount of cellular elongation and microcolony formation, typical of $\mathrm{B} / \mathrm{r}$ at the same dose (Payne, Hartman, Mudd \& Phillips, 1956; Hill \& Simson, 1961).

The tentative diagnosis of $\mathbf{B}_{\mathrm{S}}$ mutants was confirmed or refuted by macroscopic re-examination of the spread areas, after re-incubation overnight. Areas containing в or $\mathrm{B} / \mathrm{r}$ showed dense confluent growth while areas containing u.v. sensitive mutants showed considerably less growth. The most sensitive showed either no growth or only a few isolated colonies. Occasionally, areas which had been tentatively diagnosed as containing $\mathbf{B}_{\mathbf{s}}$ mutants showed a faint film of growth. Subsequent determination of the survival curves showed that these were slow-growing $\mathbf{B} / \mathbf{r}$ types. In two cases, the tentative diagnosis of $\mathbf{B}$ on the basis of the formation of snakes was refuted by the scanty growth overnight and the survival curves for these showed that they were $\mathrm{B}_{\mathrm{s}}$ mutants.

The procedure used to determine the u.v. survival curves for the bacteria was the same as the preceding except that measured samples were spread on nutrient broth agar and irradiated with a range of doses. Bacteriophage $\mathbf{T} I$ was irradiated while suspended in $2 \%$ ammonium acetate. Its survival, using the different bacterial strains as hosts, was determined by the agar layer method (Adams, 1950). The apparatus used for irradiation has been described previously (Hill \& Rossi, 1952). The present dose rate of the u.v. lamp at $56 \mathrm{~cm}$. is $8.1 \mathrm{ergs} / \mathrm{mm} .{ }^{2} / \mathrm{sec}$. as measured by a calibrated Jagger dosimeter (Jagger, 1961).

The extent of elongation of Escherichia coli cells after u.v. irradiation is dependent upon the strain and the dose (Payne et al. 1956). In order to compare more precisely the ability of the different $\mathbf{B}_{\mathrm{S}}$ mutants to elongate, the procedure described above for the tentative diagnosis of type was modified. After the survival curves were obtained, each mutant was irradiated with a dose giving about $1 \%$ survival. The extent of elongation by $3 \mathrm{hr}$ after irradiation was then classified as $1+$ to $4+$ by comparison with the length $(4+)$ of the snakes formed by $\mathbf{B}$ at $1 \%$ survival.

Sensitivity to crystal violet was determined by spreading $0.1 \mathrm{ml}$. samples of appropriate saline dilutions of broth-grown cultures on nutrient broth agar containing varying concentrations of the dye, followed by incubating at $37^{\circ}$. Exposure to crystal violet during growth slows the development of colonies. By counting the numbers of colonies appearing by a maximum of 4 days of incubation, survival 
curves for colony formation as a function of dye concentration were obtained. The times required for the appearance of colonies were also noted.

Sensitivity to furacin was determined by the gradient plate technique (Szybalski, 1952).

\section{RESULTS}

Effect of crystal violet on the isolation of $B_{\mathrm{B}}$ mutants

The numbers of $\mathrm{B}_{\mathrm{s}}, \mathrm{B} / \mathrm{r}$ and parental $\mathrm{B}$ colonies found in different isolation experiments are shown in Table 1 . The presence of $\mathbf{B} / \mathbf{r}$ colonies could be due to selection of pre-existing mutants as well as to the induction of new mutations of this type. Selection undoubtedly occurs since $B / \mathbf{r}$ mutants are more resistant both to u.v. radiation and to crystal violet than B (Bryson et al. 1951-52). Unfortunately, the evidence available on the u.v. induction of $\mathrm{B} / \mathrm{r}$ mutations in $\mathrm{B}$ organisms is scanty and equivocal (Witkin, 1947). In two reported experiments, the frequencies of B/r mutants before and after u.v. irradiation of $\mathbf{B}$ were determined. In one case,

Table 1. Frequency of radiological types among survivors of u.v. irradiation of Escherichia coli $B$

\begin{tabular}{|c|c|c|c|c|c|c|}
\hline \multirow[b]{2}{*}{ Expt. } & \multirow{2}{*}{$\begin{array}{l}\text { u.v. dose } \\
\text { (sec.) }\end{array}$} & \multirow{2}{*}{$\begin{array}{l}\text { Concen- } \\
\text { tration } \\
\quad \text { of } \\
\text { crystal } \\
\text { violet } \\
(\mu \mathrm{g} . / \mathrm{ml} .)\end{array}$} & \multirow{2}{*}{$\begin{array}{c}\text { No. of } \\
\text { colonies } \\
\text { examined }\end{array}$} & \multicolumn{3}{|c|}{ No. of colonies of } \\
\hline & & & & $\mathbf{B} / \mathbf{r}$ & $\mathbf{E}_{8}$ & B \\
\hline 1 & 80 & $\mathbf{1}$ & 11 & 1 & 1 & 9 \\
\hline $2 a$ & 80 & $\mathbf{0}$ & 100 & 7 & 1 & 92 \\
\hline$b$ & 0 & 0 & 100 & 0 & 0 & 100 \\
\hline $3 a$ & 60 & 2 & 27 & 23 & 3 & 1 \\
\hline$b$ & 40 & 2 & 54 & 47 & 2 & 5 \\
\hline$c$ & $\mathbf{0}$ & 2 & 217 & 107 & 0 & 110 \\
\hline$d$ & 80 & 1 & 60 & 13 & 2 & 45 \\
\hline$e$ & 60 & 1 & 21 & $\mathbf{5}$ & 1 & 15 \\
\hline 4 & 60 & 0 & 132 & $\mathbf{3}$ & 2 & 127 \\
\hline
\end{tabular}

the post-irradiation frequency was about ten times the frequency expected on the basis of u.v. selection, as calculated from the survival curves. However, in the second, the post-irradiation frequency was very nearly equal to the expected frequency. In the absence of definite information to the contrary, it was assumed that $\mathrm{B} / \mathrm{r}$ mutations may not be u.v. inducible in $\mathbf{B}$ and therefore that the presence of $\mathrm{B} / \mathrm{r}$ mutants among surviving colonies was due only to selection. These colonies were regarded as unavoidable 'contaminants'.

The significance of this is that in calculating the frequency of $\mathbf{B}_{\mathbf{s}}$ colonies, $\mathbf{B} / \mathbf{r}$ colonies should not be included in the total scored if they are merely contaminants. However, the possibility that some of the $\mathrm{B}_{\mathbf{s}}$ colonies might have resulted from u.v. induced mutation in the $\mathrm{B} / \mathrm{r}$ 'contaminants' also has to be considered. The unlikelihood of this can be demonstrated. For example, in experiments $3 a$ and $3 b$ (Table 1), 27 and 54 total colonies respectively were scored. In each case, these numbers were the totals appearing after the irradiation of $10^{7}$ organisms. The spontaneous frequency of $\mathrm{B} / \mathrm{r}$ in populations of $\mathrm{B}$ is about $10^{-5}$ (Witkin, 1947). Thus the 
total number of irradiated organisms must have included about $100 \mathrm{~B} / \mathrm{r}$ mutants. Since only three and two $\mathrm{B}_{\mathrm{s}}$ colonies were found in experiments $3 a$ and $3 b$ respectively, the u.v. induced mutation rate for the change from $B / r$ to $B_{\mathbf{B}}$ would have to be extremely high. However, in separate experiments where $\mathrm{B} / \mathrm{r}$ populations were irradiated to $1 \%$ survival in the presence of $1 \mu \mathrm{g}$. crystal violet per ml. of nutrient broth agar, no $\mathrm{B}_{\mathrm{S}}$ mutants were found among 412 colonies formed by surviving cells. A similar result has been reported for the u.v. irradiation of $E$. coli strain $\mathrm{K} 12$, a strain resembling $\mathrm{B} / \mathrm{r}$ in u.v. resistance. No u.v. sensitive mutants were found among 500 colonies (Howard-Flanders \& Theriot, 1962). Thus although u.v. sensitive mutants may be u.v. induced in $B / r$, the rate of induction cannot be high enough to account for the $\mathbf{B}_{\mathrm{S}}$ mutants found after the u.v. irradiation of $\mathrm{B}$ populations. The $\mathrm{B}_{\mathrm{S}}$ mutants must therefore have resulted from mutation in $\mathrm{B}$ only.

In view of the above considerations, the frequency of $\mathbf{B}_{\mathrm{S}}$ mutants was calculated as the ratio of $\mathbf{B}_{\mathbf{S}}$ colonies to the total of $\mathbf{B}$ and $\mathbf{B}_{\mathbf{S}}$ colonies. As shown in Table 2, the frequency is increased markedly when increasing concentrations of crystal violet are present during irradiation and subsequent growth.

Table 2. Effect of crystal violet concentration on frequency of $B_{\mathrm{s}}$ mutants

$\begin{array}{ccc}\begin{array}{c}\text { Concentration } \\ \text { of } \\ \text { crystal } \\ \text { violet } \\ (\mu \mathrm{g} \cdot / \mathrm{ml})\end{array} & \begin{array}{c}\mathrm{B}_{\mathrm{8}} / \mathbf{B}_{8}+\mathbf{B}^{*} \\ (\%)\end{array} & \text { Mean } \\ 0 & \mathbf{1} \% & \\ 0 & \mathbf{1} \cdot \mathbf{6} & \mathbf{1 \cdot 3} \\ 1 & \mathbf{1 0 \cdot 0} & \\ 1 & 4 \cdot 3 & \\ 1 & 6 \cdot 7 & 7 \cdot 0 \\ 2 & 75 & \\ 2 & 30 & 53\end{array}$

* The reason for excluding $\mathrm{B} / \mathrm{r}$ mutants from the denominator of this fraction is explained in the text.

\section{Properties of $B_{\mathrm{s}}$ mutants}

The u.v. survival data for small and large doses to the $\mathrm{B}_{\mathrm{s}}$ mutants are shown in Fig. 1. Although there was a wide distribution in the positions of the curves and variation in shape, all of the mutants were more u.v. sensitive than the parent $B$ strain (Fig. $1 b$ ).

The curves for the survival of colony formation when the strains were grown on agar containing varying concentrations of crystal violet were of three types. The strains were therefore compared by assigning each to a type, as illustrated in Fig. 2. Type A includes strains whose survival shows a sharp decrease at crystal violet concentrations of 1-2 $\mu \mathrm{g} . / \mathrm{ml}$. Type B strains show a sharp decrease at $2-4 \mu \mathrm{g} . / \mathrm{ml}$. The survival curves for strains of type $\mathrm{C}$ show a gradual decrease for concentrations up to at least $8 \mu \mathrm{g} . / \mathrm{ml}$. Type $\mathrm{C}$ is heterogeneous; some strains showed an accelerated decrease in survival at 8-16 $\mu \mathrm{g} . / \mathrm{ml}$. while others continued to decrease at the same rate even at concentrations as high as $32 \mu \mathrm{g} . / \mathrm{ml}$. In addition, colonies of the latter appeared within $24 \mathrm{hr}$ even at $32 \mu \mathrm{g}$./ml. Thus, type $\mathrm{C}$ strains could be distinguished as $\mathrm{C}_{1}, \mathrm{C}_{2}$ and $\mathrm{C}_{3}$, in order of increasing resistance. 
Of the twelve mutant strains, nine were classified as type $\mathbf{C}$, two as type $\mathbf{B}$ and only one as type A, the most crystal violet-sensitive group. The only other type $A$ strain was the parent B (Table 3). Thus eleven of the mutants were more crystal violet-resistant than their parent. The only strain $\left(\mathrm{B}_{\mathrm{s}-11}\right)$ which was like the parent,

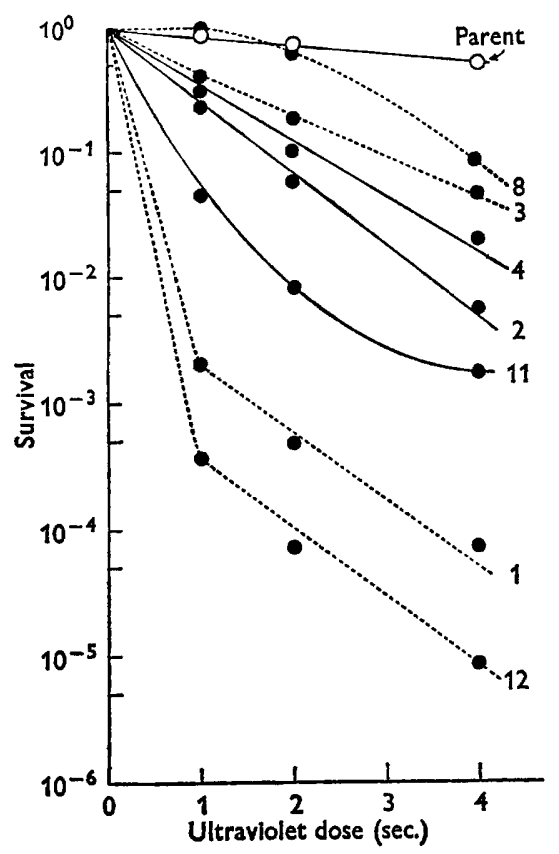

Fig. $1(a)$

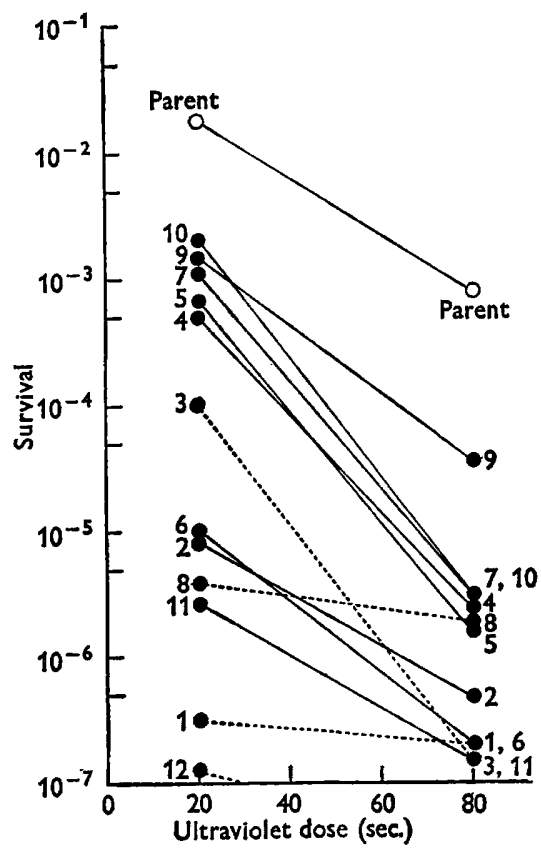

Fig. $1(b)$

Fig. 1. Survival of u.v. sensitive mutants of Escherichia coli $\mathrm{B}$ after small and large doses of u.v. radiation. Dotted curves are for those mutants which are unable to repair u.v. induced damage in bacteriophage $\mathbf{T} 1\left(h c r^{-}\right)$.

Table 3. Properties of $B_{\mathrm{S}}$ mutants

Strain Isolated

\begin{tabular}{|c|c|c|c|}
\hline & & Inhibitory & \\
\hline $\begin{array}{l}\text { Elongation } \\
\text { after u.v. } \\
\text { irradiation }\end{array}$ & $\begin{array}{l}\text { Sensitivity to } \\
\text { crystal violet } \\
\text { (type) }\end{array}$ & $\begin{array}{l}\text { concentration } \\
\text { of furacin } \\
(\mu \mathrm{g} . / \mathrm{ml} .)\end{array}$ & $\begin{array}{l}\text { Ability to } \\
\text { repair T } 1 \\
\left(h c r^{+} \text {or hcr-) }\right.\end{array}$ \\
\hline
\end{tabular}

$\begin{array}{ll}\mathbf{B} & - \\ \mathbf{B} / \mathbf{r} & 1 \\ \mathbf{B}_{\mathrm{g}-1} & 1 \\ \mathbf{B}_{\mathrm{B}-2} & 2 \\ \mathbf{B}_{\mathrm{s}-3} & 3 a \\ \mathbf{B}_{\mathrm{8}-4} & 3 a \\ \mathbf{B}_{8-5} & 3 a \\ \mathbf{B}_{\mathrm{g}-6} & 3 b \\ \mathbf{B}_{\mathrm{g}-7} & 3 b \\ \mathbf{B}_{8-8} & 3 d \\ \mathbf{B}_{8-9} & 3 d \\ \mathbf{B}_{8-10} & 3 e \\ \mathbf{B}_{\mathrm{s}-11} & 4 \\ \mathbf{B}_{8-12} & 4\end{array}$

$\begin{array}{ll}4+ & \text { A } \\ 2+ & \text { C3 } \\ 1+ & \text { C2 } \\ 1+ & \text { C1 } \\ 4+ & \text { B } \\ 2+ & \text { C2 } \\ 2+ & \text { C2 } \\ 2+ & \text { C2 } \\ 2+ & \text { C2 } \\ 2+ & \text { C3 } \\ 2+ & \text { C3 } \\ 2+ & \text { C2 } \\ 1+ & \text { A } \\ 4+ & \text { B }\end{array}$

$\begin{array}{ll}0 \cdot 25 & + \\ 3 \cdot 3 & + \\ 0 \cdot 23 & - \\ 0 \cdot 53 & + \\ 0 \cdot 25 & - \\ 0 \cdot 75 & + \\ 0 \cdot 67 & + \\ 0 \cdot 53 & + \\ 0 \cdot 59 & + \\ 0 \cdot 87 & - \\ 0.59 & + \\ 0.73 & + \\ 0.20 & + \\ 0.20 & -\end{array}$

* See Table 1. 
had been isolated without the use of crystal violet. However, this is probably without significance since, although $\mathrm{B}_{\mathrm{8}-2}$ and $\mathrm{B}_{\mathrm{s}-12}$ were also isolated in this way, they were classified as types $\mathbf{C}$ and $\mathbf{B}$, respectively.

Two different survival curves were obtained when the mutants were used as hosts for u.v. irradiated bacteriophage $\mathrm{T} 1$. The change in slope shown in the upper curve of Fig. 3 has been interpreted as indicating that the host organism can repair

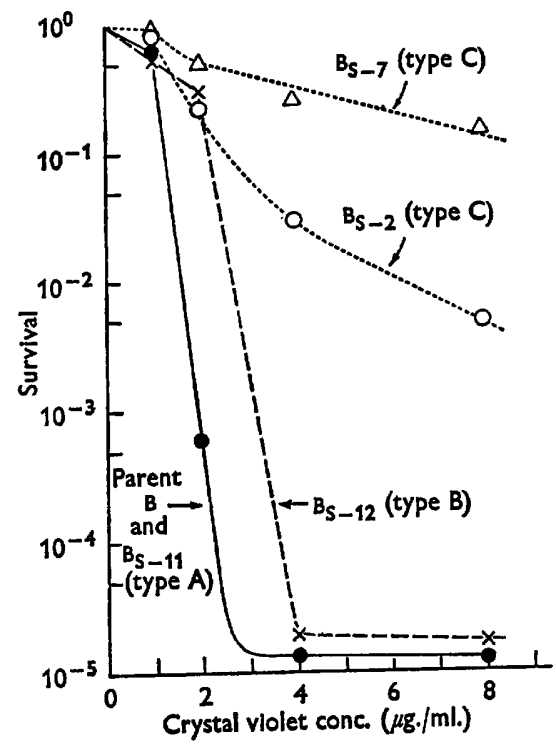

Fig. 2

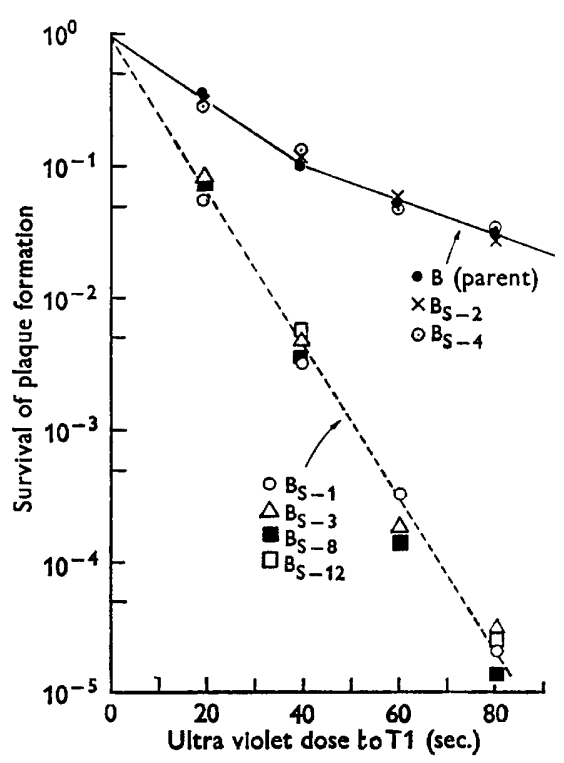

Fig. 3

Fig. 2. Types of survival curves shown by $\mathbf{B}_{\mathrm{g}}$ mutants when grown in the presence of crystal violet.

Fig. 3. Survival of u.v. irradiated bacteriophage $T 1$ when measured by using different $B_{s}$ mutants as host organisms.

a fraction of u.v. induced damage in T1 (Garen \& Zinder, 1955; Harm, 1963). Strains giving this curve have been designated as $h c r^{+}$(host cell reparability is positive). The lower curve of Fig. 3 is characteristic of $h c r^{-}$strains. Eight of the mutants gave the same $h \mathrm{cr}^{+}$curve and four gave the same hcr- curve.

In regard to sensitivity to furacin, four of the mutants were as sensitive as the parent and eight were more resistant (Table 3). None of the latter were as resistant as the $\mathbf{B} / \mathbf{r}$ strain used for comparison. Similarly, none of the mutants of type $\mathbf{C}$ with respect to crystal violet resistance were as resistant as this $\mathrm{B} / \mathrm{r}$. Therefore other $\mathrm{B} / \mathrm{r}$ strains in our collection were examined. One $\mathrm{B} / \mathbf{r}$, a tryptophan-deficient auxotroph used in other studies, showed a crystal violet survival curve identical to that shown by $\mathbf{B}_{\mathrm{s}-2}$. Two other $\mathrm{B} / \mathrm{r}$ mutants were inhibited by about $0 \cdot 75 \mu \mathrm{g}$. furacin $/ \mathrm{ml}$., as were two of the $\mathrm{B}_{\mathrm{S}}$ mutants.

Comparison of the twelve $B_{\mathrm{s}}$ mutants (Table 3, Figs. 1 and 2) showed possibly nine different phenotypes. Four of these were represented by the four hcr- strains. Although $\mathbf{B}_{\mathrm{S}-3}$ and $\mathbf{B}_{\mathrm{S}-12}$ were identical in snake formation and antibiotic resistance, 
their u.v. survival curves were distinctly different. $\mathbf{B}_{\mathrm{s}-1}$ and $\mathbf{B}_{\mathrm{s}-8}$ differed from $\mathrm{B}_{\mathrm{S}-3}$ and $\mathrm{B}_{\mathrm{B}-12}$ in snake formation and crystal violet resistance and differed from each other in crystal violet resistance, in furacin resistance and in their u.v. survival curves. The eight $h c r^{+}$strains gave an additional five phenotypes. $\mathbf{B}_{\mathrm{s}-11}$ differed from all the other $h \mathrm{rr}^{+}$strains in that it had the same sensitivity to the antibiotics as the $\mathrm{B}$ parent. $\mathbf{B}_{\mathrm{B}-9}$ was like the $h c r^{-} \mathbf{B}_{\mathrm{S}-8}$ in having the greatest resistance to crystal violet and in addition, had the greatest resistance to high doses of u.v. radiation of all the $\mathbf{B}_{\mathrm{S}}$ strains. Of the other six $h \mathrm{cr}^{+}$strains, $\mathbf{B}_{\mathrm{s}-2}$ could be differentiated by its crystal violet and $u . v$. curve and $\mathbf{B}_{\mathrm{s}-6}$ by the fact that, although it was like $\mathrm{B}_{\mathrm{S}-4}, \mathrm{~B}_{\mathrm{S}-5}, \mathrm{~B}_{\mathrm{S}-7}$ and $\mathrm{B}_{\mathrm{S}-10}$ in degree of elongation and antibiotic resistance, its u.v. curve was very close to that for $\mathbf{B}_{\mathrm{B}-2}$. Only $\mathrm{B}_{\mathrm{S}-4}, \mathbf{B}_{\mathrm{S}-5}, \mathbf{B}_{\mathrm{S}-7}$ and $\mathbf{B}_{\mathrm{S}-10}$ may have been identical.

\section{DISCUSSION}

The finding that $\mathrm{B}_{\mathrm{s}}$ mutants tend to be more crystal violet resistant than $B$ suggests that the mechanism by which crystal violet increases their frequency among colonies formed by u.v. irradiated B organisms is probably selective. This would not be a selection of pre-existing mutants. Rather, those parental organisms which survive irradiation but mutate to the $\mathbf{B}_{\mathbf{s}}$ form would have a selective advantage during subsequent growth in the presence of the dye over those survivors which do not mutate. Since the use of crystal violet alone does not select $\mathrm{B}_{\mathrm{S}}$ mutants to a detectable extent (Table 1), it seems likely that they originated by u.v. induced mutation rather than by spontaneous mutation during post-irradiation growth on agar. In this respect, mutation to increased u.v. sensitivity may differ from mutation to increased u.v. resistance since, as mentioned previously, the latter may not be u.v. inducible.

The wide distribution which was observed for the positions of the u.v. survival curves is independent of whether the $\mathbf{B}_{\mathrm{s}}$ mutants are $\mathrm{hcr}^{+}$or $\mathrm{hcr}^{-}$. A similar spread has been reported for hor- u.v. sensitive mutants of Escherichia coli $\mathrm{x} 12$ (HowardFlanders \& Theriot, 1962). It has been suggested that the hor property is determined by the ability of the organism to produce an enzyme for the repair of u.v. induced damage to DNA (Sauerbier, 1961). The fact that hor- mutants are not equally u.v. sensitive may mean that the amount of this enzyme is more critical for the survival of the u.v. irradiated bacterium. In addition, it seems clear that u.v. sensitivity is determined by a number of factors rather than by only one (Howard-Flanders \& Theriot, 1962). A second factor which has been proposed is injury to cell division, manifested by the formation of snake-like filaments after irradiation. According to cytological studies, 'snake' formation is due to continuous nuclear replication and cytoplasmic increase without cell division (Payne et al. 1956). A third factor is suggested by the present finding that the hor $r^{-}$mutants $B_{\mathrm{S}-3}$ and $\mathrm{B}_{\mathrm{S}-12}$ formed 'snakes' after u.v. irradiation like the parent B strain. Apparently these mutants can replicate their DNA in spite of inability to repair it. It has been suggested that DNA replication without repair results in mutation (Witkin, 1961). Therefore the increased u.v. sensitivity of $\mathrm{B}_{\mathrm{s}-3}$ and $\mathrm{B}_{\mathrm{s}-12}$ might be due to a combination of the herproperty and the production of new mutations which subsequently reduce the probability of recovery from the u.v. induced damage to cell division even more than it is reduced in the case of the $h c r^{+}$parent $\mathrm{B}$. 
Injury to cell division (manifested by snake-formation) is produced by exposure to other agents besides radiation. These include crystal violet and furacin. It has been suggested that snake formation and sensitivity to these antibiotics are correlated properties (Payne et al. 1956; Rörsch et al. 1962). However, the present results show that this is not always the case. Although $\mathbf{B}_{\mathrm{s}-3}$ and $\mathbf{B}_{\mathrm{s}-12}$ are snake formers after irradiation like their parent, they show an increased resistance to crystal violet but not to furacin. A possible explanation would involve a combination of $(a)$ differences in the efficiency with which different agents injure the mechanism of cell division, and $(b)$ quantitative differences in whatever metabolic property is responsible for eventual recovery from injury to cell division. The results with $\mathbf{B}_{\mathrm{S}-3}$ and $\mathrm{B}_{\mathrm{S}-12}$ suggest that the order of decreasing efficiency may be u.v. radiation, furacin, crystal violet. This is supported by the observation that unlike Escherichia coli strain B, in $E$. coli strain s, selection for increased furacin resistance is not always equivalent to selection for increased u.v. resistance (Szybalski \& Nelson, 1954; Woody-Karrer \& Greenberg, 1963). Furthermore when strain s mutates to increased u.v. resistance, there may or may not be a reduction in snake formation (Curry \& Greenberg, 1962). Thus an increased ability to recover from injury to cell division may not be the only cause of increased resistance to u.v. radiation. It would be interesting to know whether strain $\mathrm{s}$ is $h c r^{-}$. If it is, then increased u.v. resistance could be due to mutation to $h c r^{+}$. If it is already $h c r^{+}$, the increased u.v. resistance of mutants which still form snakes after u.v. irradiation would suggest that there is a fourth mechanism of u.v. induced lethality in addition to those already mentioned. In any case, it is clear from the results with strain s and with the u.v. sensitive mutants of strain $B$ that neither snake formation nor sensitivity to crystal violet and furacin are infallible indicators of u.v. sensitivity.

The diversity of $\mathbf{B}_{\mathbf{s}}$ phenotypes reported here is not surprising since mutants with increased radio-resistance are also heterogeneous (Witkin, 1947; Woody-Karrer \& Greenberg, 1963; Greenberg \& Woody-Karrer, 1963). An interesting feature of the present results is that with the exception of $\mathrm{B}_{\mathrm{s}-11}$, all of the U.v. sensitive mutants differed from their B parent in more than one property. If failure to form snakes, crystal violet resistance and furacin resistance are considered as manifestations of a single property affecting cell division even though the magnitude of the change may vary so that all three aspects may not appear simultaneously, at least two properties changed in eleven of the twelve mutants. One change, either increased resistance to crystal violet alone or to both crystal violet and furacin is presumably related to a decreased u.v. sensitivity while the other, loss of ability to propagate u.v. irradiated T1 or some unknown change, presumably increases u.v. sensitivity.

The occurrence of multiple phenotypic changes as a result either of spontaneous mutation or of exposure to u.v. radiation is a fairly common phenomenon. In some cases, such as mutants of bacteriophage showing both a sensitivity to the presence of a suppressor gene in the host organism and an altered plaque morphology, there has been mutation at different loci (Campbell, 1961). The involvement of different genes is frequently the result of a deletion as for example in bacterial mutants exhibiting both resistance to $\mathrm{T} 1$ and a requirement for tryptophan (Yanofsky \& Lennox, 1959). On the other hand, mutation at a single site can also cause multiple phenotypic changes. In some cases, the underlying common factor is known. Examples of this include bacterial mutation causing joint resistance to 
bacteriophages $\mathrm{T} 3, \mathrm{Tr}$ and the unrelated $\mathrm{T} 4$ (the result of impaired production of the lipocarbohydrate portion of a bacterial surface site for adsorption) and bacteriophage mutation causing increased sensitivity to a suppressor gene in the host, to temperature and to $\mathrm{pH}$ extremes (the result of impaired production of an enzyme (Goebel \& Jesaitis, 1952; Campbell, 1961)). It is also known that although allelic mutants show the same primary property governed by a gene, they may differ in other respects (Demerec, 1956). Since all of the hcr ${ }^{+}$mutants except $\mathrm{B}_{\mathrm{s}-11}$ show inhibitory concentrations of furacin within a narrow range and 'type $C$ ' crystal violet survival curves, the differences between them may be allelic. $\mathbf{B}_{\mathrm{s}-3}$ and $\mathrm{B}_{\mathrm{S}-12}$ may also be allelic mutants since they are both $\mathrm{her}^{-}$, both snake-formers and show the same response to crystal violet and furacin. In any case, decision as to which of the various possibilities of genetic change is responsible for each of the $\mathrm{B}_{\mathrm{S}}$ phenotypes or groups of phenotypes must await the results of genetic analysis.

We wish to express our appreciation for the technical assistance rendered by Miss Roseanne Levitt and Miss Josephine M. Shen. This work was performed under AEC Contract AT(30-1)-2740.

\section{REFERENCES}

Adams, M. H. (1950). Methods of study of bacterial viruses. Meth. med. Res. 2, 1.

Adler, H. I. \& Copeland, J. C. (1962). Genetic analysis of radiation response in Escherichia coli. Genetics, 47, 701.

Bryson, V., Rosenblum, E., Kaplan, S., Hershey, H., Cuneo, H. \& Dittman, I. (195152). Genetic and biochemical studies of bacteria. Long Island Biol. Assoc. Annu. Rep. Biol. Lab. p. 24.

CAMpbell, A. (1961). Sensitive mutants of bacteriophage $\lambda$. Virology, 14, 22.

CURry, J. \& Greenberg, J. (1962). Filament formation in radioresistant mutants of Escherichia coli $\mathrm{s}$ after treatment with ultraviolet light and radiomimetic agents. J. Bact. 83, 38.

Demerec, M. (1956). A comparative study of certain gene loci in Salmonella. Cold Spr. Harb. Symp. quant. Biol. 21, 113.

Garen, A. \& Zinder, N. D. (1955). Radiological evidence for partial genetic homology between bacteriophage and host bacteria. Virology, 1, 347 .

Goebel, W. F. \& Jesaitis, M. A. (1952). Chemical and antiviral properties of the somatic antigen of phase II 'Sh. sonnei' and of a phage-resistant variant, II/3,4,7. Le Bacteriophage. Premier Colloque International at Royaumont, p. 66.

Greenberg, J. \& Woody-Karrer, P. (1963). Radioresistant mutants of Escherichia coli в (ORNL). Radiat. Res. $20,350$.

HARM, W. (1963). On the relationship between host-cell reactivation and UV-reactivation in UV-inactivated phages. Z. Vererb. 94, 67.

HiLl, R. F. \& Rossi, H. H. (1952). Absence of photoreactivation in T1 bacteriophage irradiated with ultraviolet in the dry state. Science, 116, 424.

HiLl, R. F. \& Simson, E. (1961). A study of radiosensitive and radio-resistant mutants of Escherichia coli strain B. J. gen. Microbiol. 24, 1.

Howard-Flanders, P. \& Theriot, L. (1962). A method for selecting radiation-sensitive mutants of Escherichia coli. Genetics, 47, 1219.

Howard-Flanders, P., Boyce, R. P., Simson, E. \& Theriot, L. (1962). A genetic locus in $E$. coli $\mathrm{K} 12$ that controls the reactivation of UV-photoproducts associated with thymine in DNA. Proc. nat. Acad. Sci., Wash. 48, 2109.

JAGGER, J. (1961). A small and inexpensive ultraviolet dose-rate meter useful in biological experiments. Radiat. Res. 14, 394. 
Payne, J. I., Hartman, P. E., Mudd, S. \& Phillips, A. W. (1956). Cytological analysis of ultraviolet-irradiated Escherichia coli. III. Reactions of a sensitive strain and its resistant mutants. J. Bact. $72,461$.

Rörsch, A., Edelman, A. \& Cohen, J. A. (1963). The gene-controlled radiation sensitivity in Escherichia coli. Biochim. biophys. acta, 68, 263.

Rörsch, A., Edelman, A., van der Kamp, C. \& Cohen, J. A. (1962). Phenotypic and genotypic characterization of radiation sensitivity in Escherichia coli B. Biochim. biophys. acta, 61, 278.

SAUERBier, W. (1961). The influence of 5-bromodeoxyuridine substitution on UVsensitivity, host-cell reactivation, and photoreactivation in $\mathrm{T} 1$ and $\mathrm{P} 22 \mathrm{H} 5$. Virology, $15,465$.

Szybalski, W. (1952). Microbial selection. I. Gradient plate technique for study of bacterial resistance. Science, 116, 46.

Szybalski, W. \& Nelson, T. C. (1954). Genetics of bacterial resistance to nitrofurans and radiation. Bact. Proc. 1954, 51.

Wrtkın, E. M. (1947). Genetics of resistance to radiation in Escherichia coli. Genetics, 32 , 221.

Witkin, E. M. (1961). Modification of mutagenesis initiated by ultraviolet light through posttreatment of bacteria with basic dyes. J. Cell. comp. Physiol. 58, Suppl. 1, 135.

Woody-Karrer, P. W. \& Greenberg, J. (1963). Resistance and cross-resistance of Escherichia coli s mutants to the radiomimetic agent nitrofurazone. J. Bact. 85, 1208.

Yanofsky, C. \& LenNox, E. S. (1959). Transduction and recombination study of linkage relationships among the genes controlling tryptophan synthesis in Escherichia coli. Virology, 8, 425. 